American Journal of Applied Sciences 8 (7): 695-702, 2011

ISSN 1546-9239

(C) 2011 Science Publications

\title{
Screening Neuropharmacological Activities of Kaempferia parviflora (Krachai Dam) in Healthy Adult Male Rats
}

\author{
${ }^{1,3}$ Thaneeya Hawiset, ${ }^{2,3}$ Supaporn Muchimapura, \\ ${ }^{2,3}$ Jintanaporn Wattanathorn and ${ }^{4}$ Bungorn Sripanidkulchai \\ ${ }^{1}$ Department of Physiology and Graduate School (Neuroscience), \\ Faculty of Medicine, Khon Kaen University, Khon Kaen, 40002, Thailand \\ ${ }^{2}$ Department of Physiology, Faculty of Medicine, \\ Khon Kaen University, Khon Kaen, 40002, Thailand \\ ${ }^{3}$ Integrative Complimentary Alternative Medicine Research Group, \\ Faculty of Medicine, Khon Kaen University, Khon Kaen, 40002, Thailand \\ ${ }^{4}$ Center for Research and Development of Herbal Health Product, \\ Faculty of Pharmaceutical Science, Khon Kaen University, 40002, Thailand
}

\begin{abstract}
Problem statement: Although the global prevalence of psychological disorders is increasing continually, the efficacies of therapeutic strategies are still very limited. Oxidative stress has been implicated in the pathogenesis of psychiatric disorders and substance possessing antioxidant activity can alleviate the mentioned conditions. Therefore, we hypothesized that Kaempferia parviflora, a medicinal plant claimed for nerve tonic, also possessed the neuropharmacological activities which provide the advantage for psychiatric disorders. Approach: Adult male Wistar rats, weighing 180-220 grams, were orally given the ethanolic extract of K. parviflora at doses of 150, 200 and $250 \mathrm{mg} \mathrm{kg}^{-1} \mathrm{BW}$ once daily for 2 weeks. Then, they were determined the neuropharmacological activities including anxiolytic, anti-depression like behavior and cognitive enhancement after single dose, 1 and 2 weeks of treatment. Results: $K$. parviflora possessed anti-depression like behavior and cognitive enhancement at all treatment duration. Unfortunately, this substance failed to show anxiolytic like activity. Conclusion: Our results suggested that $K$. parviflora might be used as a novel therapeutic strategy for psychiatric disorder and cognitive enhancement. However, further investigations about precise underlying mechanism are still required.
\end{abstract}

Key words: Neuropharmacological activities, anti-depressant like activity, cognitive function, Standard Error of Mean (SEM); Analysis Of Variance (ANOVA), psychiatric disorders, antioxidant activity, oxidative stress, trained platform

\section{INTRODUCTION}

The global prevalence of mental and brain disorders, particularly anxiety, depression and dementia are intensively increased. It has been reported that approximate 52 million people throughout the world suffering from severe mental health disorders, while 150 million have mild mental disorders such as depression and anxiety and 30 million have dementia (Yousefi et al., 2010). Mental disorders are characterized by abnormalities in cognition, emotion or mood, or the highest integrative aspects of behavior (Colenda et al., 2010). To date, the available efficacies of drugs treatment for these conditions are still very limited due to their adverse side effect (Tong-Un et al., 2010a). Numerous strategies have been developed in order to increase the efficiency of treatment and decrease side effects. Therefore, the investigations of novel pharmacotherapy from medicinal plants to prevent psychiatric illnesses and cognitive impairment have significantly progressed (Chaudhari et al., 2010; Priprem et al., 2008) and obtained very much concentration.

Accumulating lines of evidence show that oxidative stress mechanism has been implicated in the pathogenesis of psychiatric and brain disorders

Corresponding Author: Supaporn Muchimapura, Department of Physiology, Faculty of Medicine, Khon Kaen University, Khon Kaen, 40002, Thailand 
(Krishnaraju et al., 2009). Recently, numerous studies demonstrated that substance possessing antioxidant activity could reduce psychiatric symptoms and improve cognitive function (Jittiwat et al., 2009; Hasan et al., 2009; Phachonpai et al., 2010; Tong-Un et al., $2010 \mathrm{a} ; 2010 \mathrm{~b} ; 2010 \mathrm{c})$. Thus, it is of interest to investigate the neuropharmacological acitivities of the medicinal plant possessing antioxidant activity.

Kaempferia parviflora Wall. ex Baker (local name, Krachai Dam, a plant in the family of Zingiberaceae) has been long term used in Thai traditional medicine. It is recommended for various ailments including allergy, fatigue, sexual dysfunction and ulcer. Moreover, it is also used as longevity promoting substance and as nerve tonic. It has been reported that alcoholic extract of $K$. parviflora rhizomes contained numerous flavonoids (Sutthanut et al., 2007) which previously reported to possess antioxidant activity, neuroprotective and cognitive enhancing effects (Spencer, 2009). Recent finding showed that the alcoholic extract of $K$. parviflora rhizome could mitigate depression-like behavior in aged rats (Wattanathorn et al., 2007). Based on the flavonoid ingredients of $K$. parviflora, its antioxidant activity and its antidepressant activity in aged rats, we hypothesized that alcoholic extract of $K$. parviflora rhizome might also possess other neuropharmacological activities. Therefore, this study was carried out to determine the effect of the plant extract on anxiety, depression and cognitive function.

\section{MATERIALS AND METHODS}

Plant material and extraction: Kaempferia parviflora rhizomes (Rom gloa variation) were collected from Tombon Boh-Park, Charttrakarn, Phitsanulok, Thailand. The herbarium was authenticated by Associated Professor Bungorn Sripanidkulchai and deposited as voucher specimen (KP-CRD 10D) at Center for Research and Development of Herbal Health Product, Faculty of Pharmaceutical Sciences, Khon Kaen University, Thailand. The dried plant rhizome powder was macerated in $95 \%$ ethanol for 4 days $\left(1 \mathrm{~kg} 2^{-1}\right.$ liters) with occasionally stirring. After filtration, the residual was further repeat macerated with $95 \%$ ethanol and then the filtrate were combined and dried by freeze dryer. The percent yield of the final product was $4.82 \%$. The extract contained total flavonoids content approximate $40.37 \mathrm{mg}$ $\mathrm{g}^{-1}$ dried powder consisting 2 main constituents 5, 7dimethoxyflavone $\left(8.789 \mathrm{mg} \mathrm{g}^{-1}\right)$ and $3,5,7,3^{\prime}, 4^{\prime}$ pentamethoxyflavone $\left(9.858 \mathrm{mg} \mathrm{g}^{-1}\right)$.
Animals: Healthy male Wistar rats (180-220 grams, 8 weeks old) were obtained from National Laboratory Animal Center, Salaya, Nakorn Pathom. They were housed in group of 4 per cage in standard metal cages at $22 \pm 2^{\circ} \mathrm{C}$ on $12: 12 \mathrm{~h}$ light-dark cycle. All animals were given access to food and water ad labium. The experiments were performed to minimize animal suffering in accordance with the internationally accepted principles for laboratory use and care of European Community (EEC directive of 1986; 86/609/EEC). The experimental protocols were approved by the Institutional Animal Care and Use Committee (AE001 50).

Drugs: Diazepam (2 mg tablet $\left.{ }^{-1}\right)$, Fluoxetine $(20 \mathrm{mg}$ tablet $^{-1}$ ), Donepezil (10 mg tablet ${ }^{-1}$ ) (Government Pharmaceutical Organization) were used as standard drugs in this study. All drugs and K. parviflora extract were dissolved in 2\% SCMC (Sodium carboxymethylcellulose) which used as vehicle to a desired concentration. Then, they were filtered through gauze and given to the animals via the intragastric feeding tube. All administered substances including the $K$. parviflora suspension were freshly prepared.

Experimental protocol: All rats were randomly divided into 6 groups. Each group contained 8 rats.

Group 1: Naïve intact control rats.

Group 2: Vehicle treated group. The animals in this group were treated with $2 \%$ Sodium carboxymethyl cellulose.

Group 3: Positive control treated group. In each test, the positive control group was treated with the standard drugs used for treating the related disorders. In the determination of anxiolytic effect, the animals were treated with Diazepam $\left(2 \mathrm{mg} \mathrm{kg}^{-1} \mathrm{BW}\right)$. In addition, the positive control treated group was treated with Fluoxetine $\left(20 \mathrm{mg} \mathrm{kg}^{-1} \mathrm{BW}\right)$ in the determination of anti-depressant effect while during the determination of cognitive function, the positive control group was treated with Donepezil $\left(1 \mathrm{mg} \mathrm{kg}^{-1} \mathrm{BW}\right)$.

Group 4-6: $K$. parviflora treated group. The animals were treated with the alcoholic extract of $K$. parviflora at various doses ranging from 150, 200 and $250 \mathrm{mg}$ $\mathrm{kg}^{-1}$ BW respectively via oral route for 2 weeks once daily throughout the experimental period.

The animals in all groups were assessed all behavioral tasks except that in the assessment of spontaneous locomotor behaviors, there was no positive control treated group. 
Behaviors evaluation: The rats were divided into various groups as mentioned earlier. The behavioral profiles were assessed both after the single dose and after the repetitive administrations of $K$. parviflora extract ( 1 and 2 weeks). Each animal was subjected to the following behavior task forces (a) Elevated plus maze test (b) Forced swimming test (c) Morris water maze test (d) Stereotypy behaviors.

Elevated plus maze test: The elevated plus maze for rat consisted of opened arms $(50 \times 10 \mathrm{~cm})$ and two enclosed arms $(50 \times 10 \mathrm{~cm})$ with $40 \mathrm{~cm}$ high walls, extending from a central platform $(10 \times 10 \mathrm{~cm})$. The arms were connected with a central square, $10 \times 10 \mathrm{~cm}$, to give the apparatus a plus sign appearance. The maze was raised to a height of $50 \mathrm{~cm}$ above floor. The maze floor and walls were constructed from dark opaque wood. Each rat was placed on the center of the platform facing an enclosed arm. Animals were recorded the number of opened arms entries and the time spent in the opened arms within $5 \mathrm{~min}$. The maze was cleaned following each trial to remove any residue or odors. Each rat was assessed individually 30 min after the treatment.

Forced swimming test: In order to assess the antidepression like behavior of the plant extract, the modified (Tong-Un et al., 2010a) test was conducted. The apparatus used in this study is the cylinder glass aquarium $(22 \mathrm{~cm}$ diameter $\times 40 \mathrm{~cm}$ high) filled to the depth of $20 \mathrm{~cm}$ with fresh water at $25^{\circ} \mathrm{C}$. After $30 \mathrm{~min}$ of drug administration, each animal was placed individually into the cylinder for 5 minute-test and observed for swimming (movement throughout the swimming chamber) and immobility (by keeping the head of the animals above water in the way that animal made no further attempts to escape) by blind observer who has been trained for the observation. Upon removal from the water, rats were towel-dried and finally returned to their home cage.

Morris water maze test: The water maze consisted of a metal pool $(170 \mathrm{~cm}$ in diameter $\times 58 \mathrm{~cm}$ tall $)$ filled with tap water $\left(25^{\circ} \mathrm{C}, 40 \mathrm{~cm}\right.$ deep). In the center of one quadrant was a removable escape platform below the water level and covered with a nontoxic milk powder. The pool was divided into four quadrants (NE, NW, SE and SW) by two imaginary lines crossing the center of the pool. For each animal, the location of invisible platform was placed at the center of one quadrant and remained there throughout training. The rats must memorize the platform location in relation to various environmental cues because there was nothing directly shows the location of the escape platform in and outside the pool. Therefore, the placement of the water tank and platform were the same in all acquisition trials. Each rat was gently placed in the water facing the wall of the pool from one of the four starting points (N, E, S, or W) along the perimeter of the pool and the animal was allowed to swim until it found and climbed onto the platform. During training session, the subject was gently placed on the platform by the experimenter when it could not reach the platform in 60 second. In either case, the subject was left on the platform for 15 second and removed from the pool. The time for animals to climb on the hidden platform was recorded as escape latency or acquisition time. In addition to the acquisition test, the determination of retention memory was carried out on the next day. According to this test, the platform was removed and the animals were placed into the water maze for 60 second. The retention of memory or the time that the animal spent to swim around the previous location of platform before removing the platform on the test occurring in the next day was also recorded. It has been postulated that if the spatial memory of the rat for the trained platform location is accurate, the rat will swim to the platform location and search around the exact location. Therefore, the more accurate the spatial memory is, the greater the number of times rat swim across the trained platform. In each trial, the animal was quickly dried with towel before being returned to the cage. All test in Morris water maze tests were carried out within $30 \mathrm{~min}$ after the plant extract administration of the substances. Any enhancement of cognition would be reflected by a decrease in escape latency time but increase in retention time.

Stereotypy behaviors: In order to assure that anxiolytic, anti-depression like behavior and cognitive enhancing effect which determined by various tests just mentioned earlier were not false positive due to the effect of $K$. parviflora on motor behaviors, we also determined the effect of $K$. parviflora on the spontaneous locomotor activities by open field test (Joshua et al., 2010). The open field apparatus was an arena $80 \mathrm{~cm}$ in diameter with a white, opaque wall 30 $\mathrm{cm}$ high. Rats were individually placed in the center of the arena and locomotor activities including the number of grooming, licking and rearing were scored within $5 \mathrm{~min}$.

Statistical analysis: Data were presented as mean \pm Standard Error of Mean (SEM) (Adeyemi, 2009; Zareian et al., 2010). One-way Analysis Of Variance (ANOVA) (Parsakhoo et al., 2009; Zareian et al., 2010; Iqbal and Khan, 2010; Hashemi, 2010), followed by Duncan's test. A probability level less than 0.05 were accepted as significance. 


\section{RESULTS}

Effect of $K$. parviflora on anxiolytic like behavior: The anxilytic like behavior of $K$. parviflora was determined using elevated plus maze and the results were shown in Fig. 1-2. It was clearly demonstrated that oral administration of SCMC (Sodium carboxymethyl-cellulose) or vehicle produced no significant changes in both the number of opened arms entries and time spent in the opened arms after single and repetitive doses.

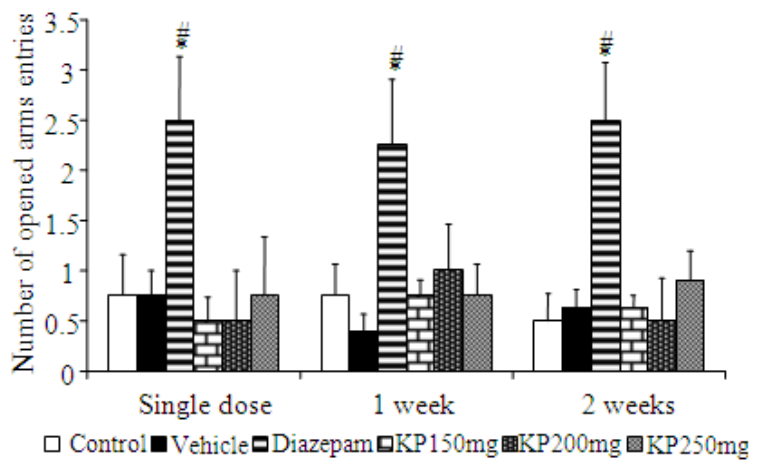

Fig. 1: Effect of Diazepam and K. parviflora (150, 200 and $250 \mathrm{mg} \mathrm{kg}^{-1} \mathrm{BW}$ ) on the number of opened arms entries in elevated plus maze test. Data were presented as mean \pm SEM $\left(\mathrm{n}=8\right.$ group $\left.^{-1}\right)$. \#, * P-value $<0.05$ compared with control and vehicle treated group respectively

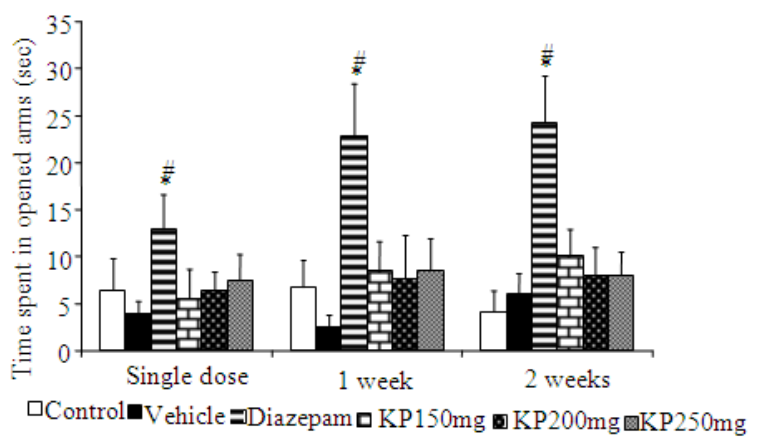

Fig. 2: Effect of Diazepam and K. parviflora (150, 200 and $250 \mathrm{mg} \mathrm{kg}^{-1} \mathrm{BW}$ ) on the time spent in opened arms in elevated plus maze test. Data were presented as mean \pm SEM $\left(n=8\right.$ group $\left.^{-1}\right)$. $\#$, * P-value $<0.05$ compared with control and vehicle treated group respectively
Diazepam, a standard drug used for the treatment of anxiety, which used as positive control in this study significantly increased the number of opened arms entries and time spent in the opened arms at all duration of treatment (p-value $<0.05$ all; compared to that of control and vehicle treated groups). Unfortunately, administration of ethanolic extract of $K$. parviflora failed to show significant changes in both parameters.

Effect of $K$. parviflora on anti-depression like behavior: The effect of $K$. parviflora on antidepression like behavior was determined using forced swimming test, a valid tool using for the screening the effect of substances possessing anti-depressant activity and the neurobilogical mechanism related to depression (Bruchey and Gonzalez-Lima, 2008). The results demonstrated that rats subjected to vehicle administration did not produce significant changes in immobility and swimming times in forced swimming test throughout the observation time, while the rats treated with Fluoxetine and K. parviflora at all dosage rang used in this study significantly decreased immobility time but increased swimming time in forced swimming test after single dose of administration and these changes still existed when the treatment was prolonged further to 1-2 weeks (p-value $<0.05$ all; compared with control and vehicle treated groups) as shown in Fig. 3-4 respectively.

Effect of $K$. parviflora on spatial learning and memory: To determine the cognitive enhancing effect of $K$. parviflora using Morris water maze test, a valid test which is sensitive to the spatial learning and memory abilities or hippocampus-dependent memory (Mehrdad et al., 2008). The present results showed no significant changes in escape latency and retention times in control and vehicle treated group. However, rats which received either Donepezil (a cholinesterase inhibitor) or $K$. parviflora significantly decreased escape latency time but increased retention time (pvalue $<0.05$, all; compared with control and vehicle treated groups) (Fig. 5-6).

Effect of $K$. parviflora on spontaneous locomotor activities: In order to assure that the anxiolytic, antidepression like behavior and cognitive enhancing effect which determined by various tests just mentioned earlier were not false positive induced by the effect of $K$. parviflora on motor behaviors, we also determined the effect of $K$. parviflora on the spontaneous locomotor activities and the results were shown in Fig. 7-9. It was found that the rats subjected to $K$. parviflora treatment at the dosage range used in this study did not produce significant changes on spontaneous motor behaviors including grooming, rearing and licking after both single and repetitive administrations of the plant extract. 


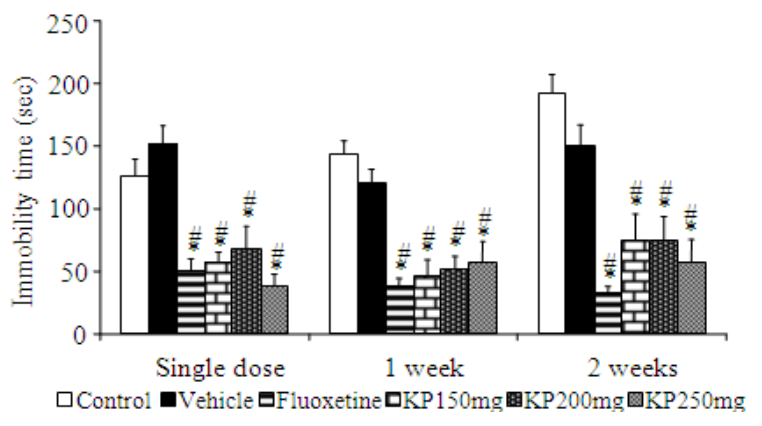

Fig. 3: Effect of Fluoxetine and K. parviflora (150, 200 and $250 \mathrm{mg} \mathrm{kg}^{-1} \mathrm{BW}$ ) on immobility time in forced swimming test. Data were presented as mean \pm SEM $\left(\mathrm{n}=8\right.$ group $\left.^{-1}\right)$. \#, * P-value $<0.05$ compared with control and vehicle treated group respectively

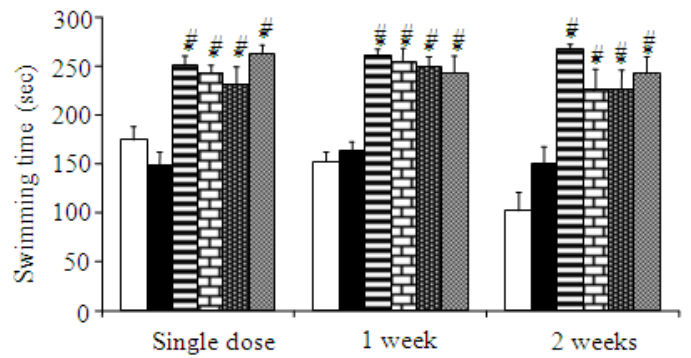

$\square$ Control Vehicle EFluoxetine $\square \mathrm{KP} 150 \mathrm{mg}$ 固 KP200mg $\mathrm{KP} 250 \mathrm{mg}$

Fig. 4: Effect of Fluoxetine and K. parviflora $(150,200$ and $250 \mathrm{mg} \mathrm{kg}^{-1} \mathrm{BW}$ ) on swimming time in forced swimming test. Data were presented as mean \pm SEM $\left(n=8\right.$ group $\left.^{-1}\right)$. \#, * P-value $<0.05$ compared with control and vehicle treated group respectively

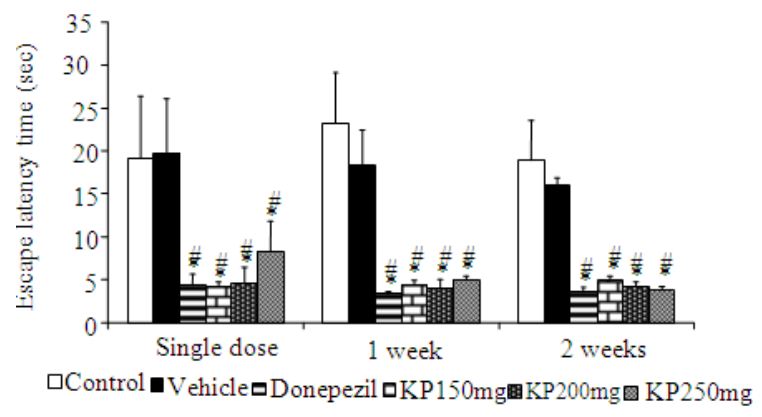

Fig. 5: The cognitive enhancing effect of Donepezil and K. parviflora $\left(150,200\right.$ and $\left.250 \mathrm{mg} \mathrm{kg}^{-1} \mathrm{BW}\right)$ on escape latency time in Morris water maze test. Data were presented as mean \pm SEM $(n=8$ group $^{-1}$ ). \#, * P-value $<0.05$ compared with control and vehicle treated group respectively

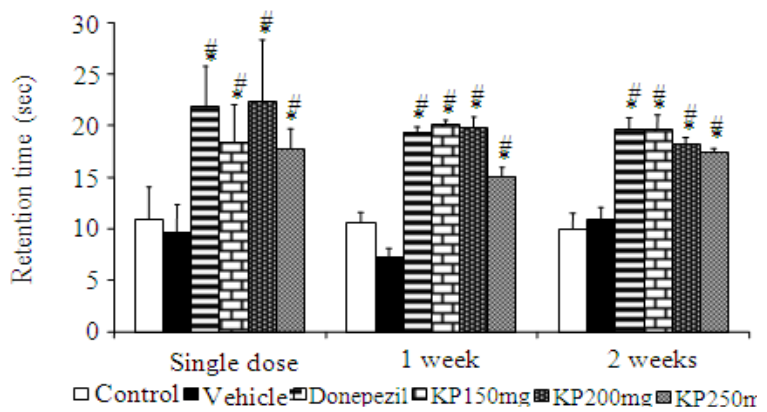

Fig. 6: The cognitive enhancing effect of Donepezil and $K$. parviflora $\left(150,200\right.$ and $250 \mathrm{mg} \mathrm{kg}^{-1}$ $\mathrm{BW})$ on retention time in Morris water maze test. Data were presented as mean \pm SEM $(n=8$ group $^{-1}$ ). \#, * P-value $<0.05$ compared with control and vehicle treated group respectively

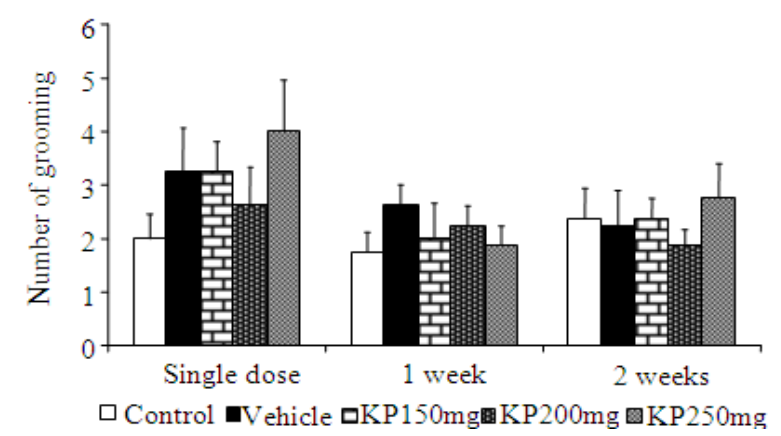

Fig. 7: $\quad$ Effect of $K$. parviflora on grooming behavior. Rats were treated with either vehicle or $K$. parviflora at various doses ranging from 150 , 200 and $250 \mathrm{mg} \mathrm{kg}^{-1}$ BW via intragastric routes for 2 weeks, then they were determined the number of grooming behavior. Data were presented as mean \pm SEM $\left(n=8\right.$ group $\left.^{-1}\right)$

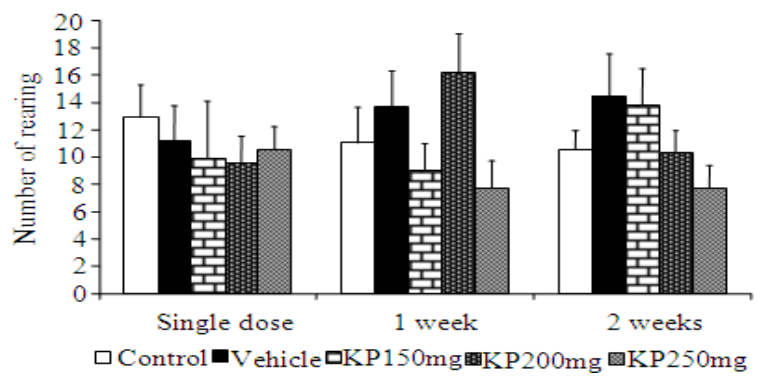

Fig. 8: Effect of $K$. parviflora on rearing behavior. Rats were treated with either vehicle or $K$. parviflora at various doses ranging from 150 , 200 and $250 \mathrm{mg} \mathrm{kg}^{-1}$ BW via intragastric routes for 2 weeks, then they were determined the number of rearing behavior. Data were presented as mean \pm SEM $\left(n=8\right.$ group $\left.^{-1}\right)$ 


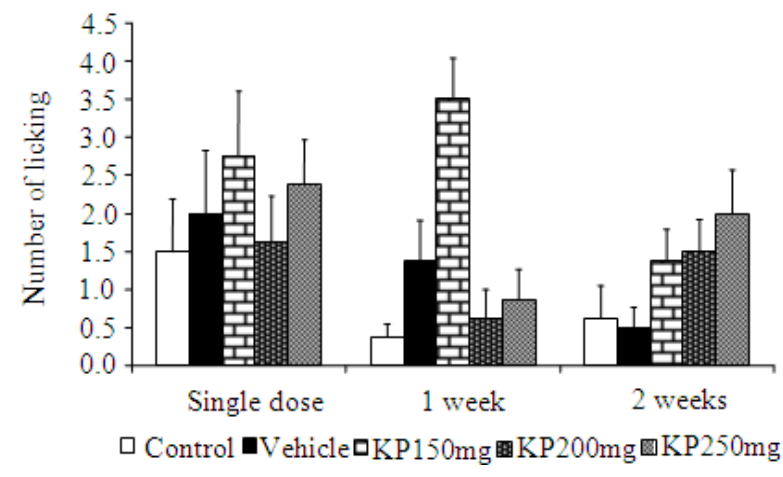

Fig. 9: Effect of $K$. parviflora on licking behavior. Rats were treated with either vehicle or $K$. parviflora at various doses ranging from 150 , 200 and $250 \mathrm{mg} \mathrm{kg}^{-1}$ BW via intragastric routes for 2 weeks, then they were determined the number of licking behavior. Data were presented as mean $\pm \operatorname{SEM}\left(n=8\right.$ group $\left.^{-1}\right)$

\section{DISCUSSION}

Kaempferia parviflora, is naturally present in different varieties which are characterized by their external color. In fact, the anxiolytic and antidepression like activities of $K$. parviflora were previously studied (Wattanathorn et al., 2007). However, the mentioned effects were studied in aging rats. Thus, the current study was set up to further investigate the neuropharmacological effects of $K$. parviflora (dark color; Rom gloa variation). Previous studies had demonstrated that serotonin played a crucial role on various behavior including swimming behavior in forced swimming test (Detke et al., 1995) and learning and memory (Myhrer, 2003). It was found that serotonin contributed a crucial role on both acquisition and consolidation processes (Kumar et al., 2007). However, numerous neurotransmitters had been proposed to contribute the important role on learning and memory including acetylcholine (Zoladz and Diamond, 2008; Bustamam et al., 2008). Our findings clearly demonstrated that the alcoholic extract of $K$. parviflora rhizome enhanced swimming time while decreased immobility time in forced swimming test in the same manner as Fluoxetine, a Serotonin Reuptake Inhibitor (SSRI) (Mohajeri et al., 2007). Therefore, the current results were in agreement with previous study which demonstrated the antidepressant like activity in aging rat (Wattanathorn et al, 2007). Based on the role on serotonin on swimming behavior and memory as mentioned earlier, we suggested that the anti-depressant and cognitive enhancing effects induced by $K$. parviflora might occur partly via the enhanced available serotonin. However, the effect of plant extract on cholinergic system which also played an important role on spatial memory (Bustamam et al., 2008; TongUn et al., 2010c) still could not be excluded and required further studied.

\section{CONCLUSION}

In conclusion, the present study demonstrated the potential of $K$. parviflora both to decrease depressionlike activity and to enhance spatial memory. Therefore, $K$. parviflora may be served as the natural resource to develop the anti-depressant and cognitive enhancing agents. However, further investigation to understand the precise underlying mechanism is warranted.

\section{ACKNOWLEDGEMENT}

This study was supported by scholarships of the Graduated School, Khon Kaen University, the National Research Council of Thailand, Integrative Complimentary Alternative Medicine Research Group, Khon Kaen University, Khon Kaen, Thailand and Development of Herbal Health Product (CRD-HHP), Faculty of Pharmaceutical Science, Khon Kaen University, Thailand.

\section{REFERENCES}

Adeyemi, A.O., 2009. Bioaccumulation of arsenic by fungi. Am. J. Environ. Sci., 5: 364-370. DOI: 10.3844/ajessp.2009.364.370

Bruchey, A.K. and F. Gonzalez-Lima, 2008. Behavioral, physiological and biochemical hormetic responses to the autoxidizable dye methylene blue. Am. J. Pharmacol. Toxicol., 3: 7279. DOI: 10.3844/ajptsp.2008.72.79

Bustamam, A., S. Ibrahim, A.S. Al-Zubairi, M. MET and M.M. Syam, 2008. Zerumbone: A natural compound with anti-cholinesterase activity. Am. J. Pharmacol. Toxicol., 3: 209-211. DOI: 10.3844/ajptsp.2008.209.211

Chaudhari, U.P., A. Raje, N.D. Trivedi and A.N. Bhandari, 2010. Antidepressant like effect of $\mathrm{N}(\mathrm{G})$ -nitro-l-arginine methyl ester. Int. J. Pharmacol., 6: 183-191. DOI: 10.3923/ijp.2010.183.191

Colenda, C.C., C. Legault, S.R. Rapp, M.W. DeBon and P. Hogan et al., 2010. Psychiatric disorders and cognitive dysfunction among older postmenopausal women: results from the Women's Health Initiative Memory Study. Am. J. Geriatr. Psychiatry, 2: 177-186. PMID: 20104074

Detke, M.J., M. Rickels and I. Lucki, 1995. Active behaviors in the rat forced swimming test differentially produced by serotonergic and noradrenergic anti-depressants. Psychopharmacology (Berl), 1: 66-72. PMID: 8539342 
Hasan, S.M.R., M. Jamila, M.M. Majumder, R. Akter and M. Hossain et al., 2009. Analgesic and antioxidant activity of the hydromethanolic extract of Mikania scandens (L.) Willd. Leaves. Am. J. Pharmacol. Toxicol., 4: 1-7. DOI: 10.3844/ajptsp.2009.1.7

Hashemi, S.A., 2010. Evaluating plant species diversity and physiographical factors in natural broad leaf forest. Am. J. Environ. Sci., 6: 20-25. DOI: 10.3844/ajessp.2010.20.25

Iqbal, A.K.M.S. and A.A. Khan, 2010. Modeling and analysis of MRR, EWR and surface roughness in EDM milling through response surface methodology. Am. J. Engg. Applied Sci., 3: 611619. DOI: 10.3844/ajeassp.2010.611.619

Jittiwat, J., J. Wattanathorn, T. Tong-Un, S. Muchimapura and C. Bunchonglikitkul, 2009. Porcine brain extract attenuates memory impairments induced by focal cerebral ischemia. Am. J. Applied Sci., 9: 1662-1668. DOI: 10.3844/ajassp.2009.1662.1668

Joshua, A.J., K.S. Goudar, N. Sameera, G.P. Kumar and B. Murali et al., 2010. Safety assessment of herbal formulations, Rumbion ${ }^{\mathrm{TM}}$ and Tyrel $^{\mathrm{TM}}$ in albino Wistar rats. Am. J. Pharmacol. Toxicol., 5: 42-47. DOI: 10.3844/ajptsp.2010.42.47

Krishnaraju, A.V., C.B.M. Rao, D. Sundararaju, K. Sengupta and G. Trimurtulu, 2009. Antiinflammatory activity of Vitex leucoxylon L. Bark extracts against Freund's complete adjuvant induced arthritis in Sprague Dawley rat. Am. J. Infect. Dis., 5: 68-73. DOI: 10.3844/ajidsp.2009.68.73

Kumar, A.M., J.B. Fernandez, I. Borodowsky, L. Gonzalez and M. Kumar, 2007. HIV-1 infection and central monoamine neurotransmitters. Am. J. Infect. Dis., 3: 177-183. DOI: 10.3844/ajidsp.2007.177.183

Mehrdad, J., S. Yousef, H. Ahmad, N. Naser and P. Abbas, 2008. Working memory learning method and astrocytes number in different subfields of rat's hippocampus. Am. J. Anim. Vet. Sci., 3: 28-31. DOI: 10.3844/ajavsp.2008.28.31

Mohajeri, D., G. Mousavi, M. Mesgari, Y. Doustar and Mir H.K. Nouri, 2007. Subacute toxicity of Crocus Sativus L. (Saffron) stigma ethanolic extract in rats. Am. J. Pharmacol. Toxicol., 2: 189-193. DOI: 10.3844/ajptsp.2007.189.193

Myhrer, T., 2003. Neurotransmitter systems involved in learning and memory in the rat: a meta-analysis based on studies of four behavioral tasks. Brain Res. Rev., 41: 268-287. PMID: 12663083
Parsakhoo, A., S.A. Hosseini, M. Lotfalian and H. jalilvand, 2009. Influence of hillside gradient on forest road cross section components in a loamy clay soil. Am. J. Applied Sci., 6: 1212-1216. DOI: 10.3844/ajassp.2009.1212.1216

Phachonpai, W., J. Wattanathorn, S. Muchimapura, T. Tong-Un and D. Preechagoon, 2010. Neuroprotective effect of Quercetin encapsulated liposomes: a novel therapeutic strategy against Alzheimer's disease. Am. J. Applied Sci., 4: 480485. DOI: 10.3844/ajassp.2010.480.485

Priprem, A., J. Watanatorn, S. Sutthiparinyanont, W. Phachonpai and S. Muchimapura, 2008. Anxiety and cognitive effects of quercetin liposomes in rats. Nanomedicine: Nanotech. Biol. Med., 4: 7078. DOI: 10.1016/j.nano.2007.12.001

Spencer, J.P., 2009. Flavonoids and brain health: multiple effects underpinned by common mechanisms. Genes Nutr., 4: 243-50. PMID: 19685255

Sutthanut, K., B. Sripanidkulchai, C. Yenjai and M. Jay, 2007. Simultaneous identification and quantitation of 11 flavonoid constituents in Kaempferia parviflora by gas chromatography. J. Chromatogr. A., 1143: 227-233. DOI: 10.1016/j.chroma.2007.01.033

Tong-Un, T., P. Wannanon, J. Wattanathorn and W. Phachonpai, 2010a. Quercetin liposomes via nasal administration reduce anxiety and depression-like behaviors and enhance cognitive performances in rats. Am. J. Pharmacol. Toxicol., 5: 80-88. DOI: 10.3844/ajptsp.2010.80.88

Tong-Un, T., S. Muchimapura, J. Wattanathorn and W. Phachonpai, 2010b. Nasal administration of Quercetin liposomes improves memory impairment and neurodegeneration in animal model of Alzheimer's disease. Am. J. Agri. Biol. Sci., 5: 286-293. DOI: 10.3844/ajabssp.2010.286.293

Tong-Un, T., P. Wannanon, J. Wattanathorn and W. Phachonpai, 2010c. Cognitive-enhancing and antioxidant activities of Quercetin liposomes in animal model of Alzheimer's disease. J. Biol. Sci., 10: 84-91. DOI: 10.3844/ojbsci.2010.84.91.

Wattanathorn, J., P. Pangpookiew, K. Sripanidkulchai, S. Muchimapura and B. Sripanidkuchai, 2007. Evaluation of the anxiolytic and antidepressant effects of alcoholic extract of Kaempferia parviflora in aged rats. Am. J. Agri. Biol. Sci., 2: 94-98. DOI: 10.3844/ajabssp.2007.94.98

Yousefi, F., M.B. Mansor, R.B. Juhari, M. Redzuan and M.A. Talib, 2010. The relationship between gender, age, depression and academic achievement. Cur. Res. Psychol., 6: 61-66. DOI: 10.3844/crpsp.2010.61.66 
Zareian, P., A.S. Jahromi, F.H. Rad and S. Zarei, 2010. Do resistin and tumor necrosis factor- $\alpha$ relate to changes in insulin resistance in normal pregnancy?. Am. J. Biochem. Biotech., 6: 19-24. DOI: 10.3844/ajbbsp.2010.19.24
Zoladz, P.R. and D.M. Diamond, 2008. Hormetic and Non-Hormetic Dose-response functions in stress effects on memory and synaptic plasticity: issues and mechanisms. Am. J. Pharmacol. Toxicol., 3: 111-124. DOI: 10.3844/ajptsp.2008.111.124 